\title{
A Design Of Ultra Wide Band Antenna With Three Notch Characteristics
}

\author{
Hengliang TANG, Jilan LI, Xin ZHANG \\ School of Electronic Information Engineering ,Wuyi University, Jiangmen Guangdong 529000, China
}

Keywords: CPW; Ultra-wide band(UWB); Triple bandnotched; Patch antenna

\begin{abstract}
In order to avoid the mutual interference between UWB system and narrowband communication system, the ultra wide band antenna with notch characteristic on diamondshaped patch antenna is improved. The coplanar wave guide (CPW) feed structure and a larger groove rectangle etching on the ground and rhombus radiating elements structure are designed to achieve ultra-wide band characteristics. An Lshaped minor radiation patch is added in the antenna ground plate to realize WiMAX and WLAN dual-band notch. An Eshaped groove on the rhombus radiating elements is etched to achieve the ITU $8 \mathrm{G}$ single notch. The simulation and experimental results show, the VSWR is less than 2 in 3 $12 \mathrm{GHz}$ operating frequency band, and this structure antenna has a good notch characteristic in the frequency of 3.2$3.7 \mathrm{GHz}, 5.1-5.8 \mathrm{GHz}$ and $8.2-8.7 \mathrm{GHz}$. In addition to the operating band of ultra-wide band range apart from three resistance bands, the antenna has good radiation characteristics and stability gain.
\end{abstract}

\section{Introduction}

With the development of indoor wireless high speed access techniques, especially the $3.1-10.6 \mathrm{GHz}$ band was used for UWB communication in the IEEE 802 15.3a standard[1], the UWB system has become more and more attractive. It has the advantages of low cost, high data transmission rate and low transmission power. However, there are other narrowband communication systems in the UWB communication, such as WIMAX (3.2-3.7GH) , Wireless LAN $(5.1-5.8 \mathrm{GHz})$ and ITU $(8.2-8.7 \mathrm{GHz})$. In order to avoid the interference between UWB system and narrow band communication system, the UWB antenna needs impedance characteristic [2]. One way to overcome the interference is increaseing the band stop filter, but it will increase the design cost and complexity of the system. Another simple and effective method is embedding different types of resonant structures in the antenna radiation patch or floor [2].

Many scholars are studying the band notched UWB antenna. In paper [3] the double notch was achieved by adding Lshaped tuning stub and etching L shaped joint. In paper [4] the double-band UWB notch characteristic in $3.5 \mathrm{GHz}$ and
5.5 GHz was achieved by etching C-shaped groove on the antenna radiation unit and adding $\mathrm{L}$-shaped tuning stub on the antenna ground. The antenna can meet the single or double notch notch radiation characteristics. All of them do not meet the requirements of miniaturization design, they are difficult to integrate, and the geometric structure of the antenna is complex.

In this paper, based on the above literature, an ultra wide band slot antenna is proposed, which is made up of coplanar waveguide and has three notch characteristics. The ultra wide band characteristics of the antenna are obtained by etching the rectangular wide slot on the diamond radiating unit on the ground floor. In this paper, the double band UWB notch characteristic in WLAN and WiMAX was achieved by adding symmetrical double L-shaped tuning stub on the antenna ground. The three notch characteristics was achieved by etching E shape groove on the antenna radiation unit [2]. The antenna was designed, modeled and optimized by Ansoft HFSS simulation software.

\section{Structural design}

In this paper, the dielectric was Rogers 4350B. Whose thickness is $0.508 \mathrm{~mm}$, dielectric constant is 3.66 and loss tangent is 0.0037. The size of this antenna is $32 \mathrm{~mm} \times 32 \mathrm{~mm} \times 0.508 \mathrm{~mm}$. The antenna in this paper was fed by CPW (coplanar waveguide). The common feeding methods of antenna are coaxial feed, microstrip line feed and coplanar waveguide feed. The microstrip antenna fed by microstrip and coplanar waveguide has the advantages of small size and easy integration. The coplanar waveguide has a wider bandwidth than the microstrip line, which avoids the instability caused by the small amount of radiation. The width of the feeder line is $1.0 \mathrm{~mm}$ that was calculated by TXLINE software. And the gap between feeder line and ground is $0.3 \mathrm{~mm}$.

Figure 1 is the structure diagram of the antenna. Figure 2 is the physical diagram of the antenna. The antenna is connected with a rectangular slot $W 1 \times L 1$ on the ground by a diamond radiation patch which is connected with a coplanar waveguide feed line. The size of E shape groove is La1,La2. The size of double L-shaped is Lb1,Lb2,Lb3. 


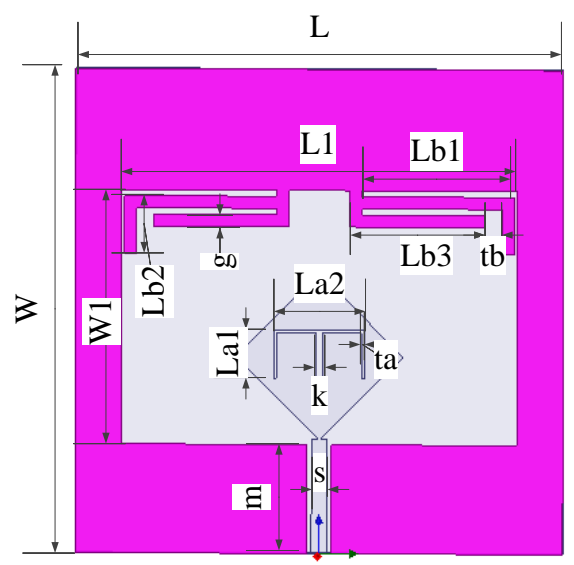

Fig. 1 The structure diagram of the antenna.

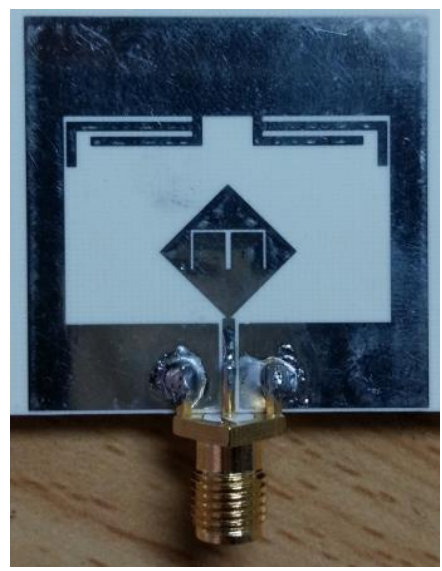

Fig. 2 The physical diagram of the antenna.

The structure of the radiation patch antenna is slotted in etching was first proposed and the most commonly used resonant structure. According to the empirical formula, the relationship between the slit length and the center frequency is

$$
f_{\text {notch }}=\frac{c}{2 l \sqrt{\left(\varepsilon_{r}+1\right) / 2}}
$$

Where $l$ is the length of the gap, $c$ is the speed of light in free space, $\varepsilon_{r}$ is relative dielectric constant. then we can get the parameters of the antenna by using Ansoft HFSS simulation software: $\mathrm{L} 1=26 \mathrm{~mm}, \mathrm{~W} 1=16.8 \mathrm{~mm}, \mathrm{La} 1=6 \mathrm{~mm}$, $\mathrm{La} 2=3 \mathrm{~mm}, \mathrm{Lb} 1=10 \mathrm{~mm}, \mathrm{Lb} 2=2.9 \mathrm{~mm}, \mathrm{Lb} 3=8.9 \mathrm{~mm}, \mathrm{k}=0.4 \mathrm{~mm}$, $\mathrm{g}=0.3 \mathrm{~mm}, \mathrm{~s}=1 \mathrm{~mm}, \quad \mathrm{dw}=0.3 \mathrm{~mm}, \mathrm{~m}=7.8 \mathrm{~mm}, \quad \mathrm{ta}=0.2 \mathrm{~mm}$, $\mathrm{tb}=0.8 \mathrm{~mm}$.

\section{Simulation and analysis}

Now we mainly discusses the influence of the E shaped slot on the VSWR of the antenna in $8.4 \mathrm{GHz}$, the simulation results are shown in Figure 3. It can be seen from Figure 3 that with the increase of La1 and La2, the high frequency band of the antenna increases, but it has little influence on the low frequency and the intermediate frequency.

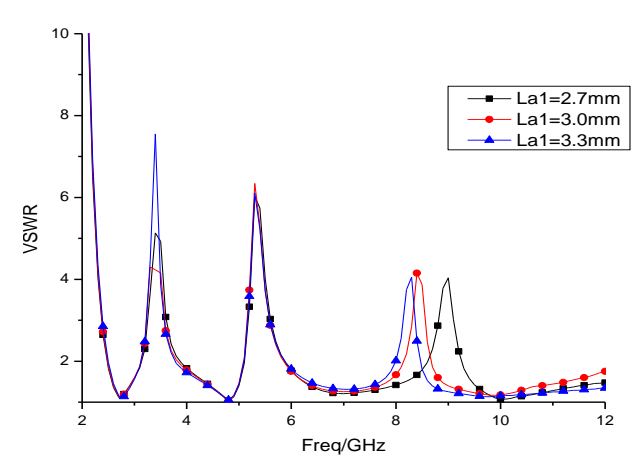

(a)

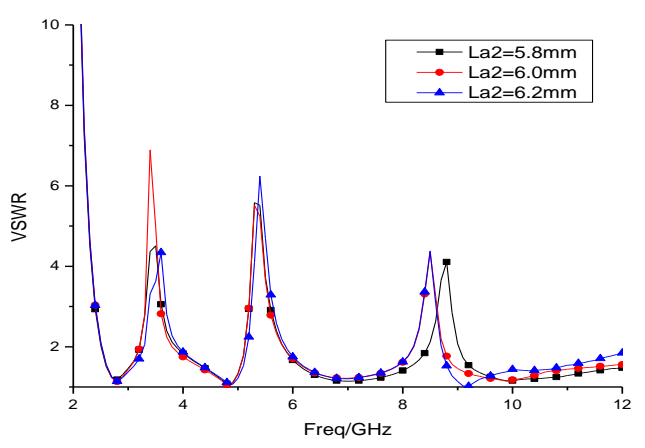

(b)

Fig. 3 The simulation results of La1 and La2 on VSWR.

In order to verify the practicability and effectiveness of the antenna, the antenna is measured. Figure 4 shows the simulation and measurement results of VSWR. As can be seen from Figure 4, when $V S W E \leq 2$, the antenna can achieve the full coverage of the UWB spectrum in $3-12 \mathrm{GHz}$, which has three stop bands in $3.4 \mathrm{GHz}, 5.4 \mathrm{GHz}$ and $8.4 \mathrm{GHz}$, respectively, it can fulfil the requirements of the ultra wide band range and the requirements of the three notch bands. Comparing the measured results with the simulation results, it can be seen that the two are in general agreement, but there are some deviations. The frequency range of the stop band is offset by simulation and measurement. The results show that the bandwidth of the stop band is slightly larger than the simulation results. The accuracy of the antenna processing, the welding technology of the SMA joint and the quality of the dielectric substrate are all the reasons for these deviations.

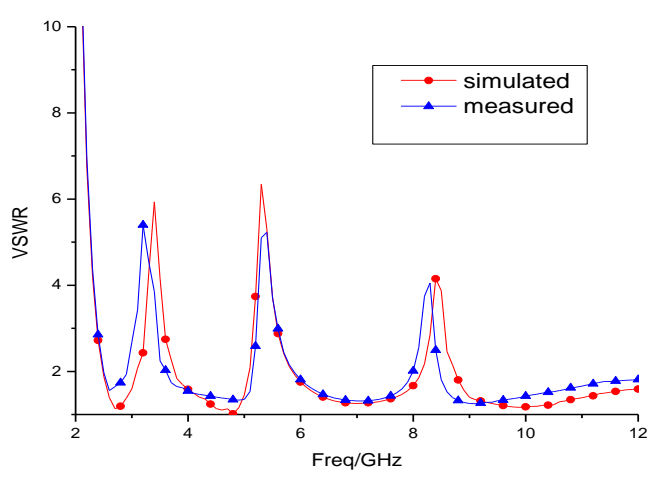

Fig. 4 The simulation and measurement results of VSWR. 
In order to get a better understanding of the principle of the notch characteristics, the surface currents near the three notch structures are simulated by using Ansoft HFSS simulation software. Figure 5 shows the simulation results of the surface current in $3.4 \mathrm{GHz}, 5.4 \mathrm{GHz}$ and $8.4 \mathrm{GHz}$ the three stop band. It can be seen from Figure 5, when the center frequency is $3.4 \mathrm{GHz}$ and $5.4 \mathrm{GHz}$, the current is mainly concentrated in the $\mathrm{L}$ shaped radiation. When the center frequency is $8.4 \mathrm{GHz}$, the current is mainly concentrated in the $\mathrm{E}$ shaped groove. In the three frequency range of the antenna, the current of the antenna is mainly concentrated in the three geometric notch structures, that is double L-shaped and E shape groove. It is shown that the energy is stored in the notch structure near the notch band, and is not radiated out. So the notch characteristics are produced in these bands.
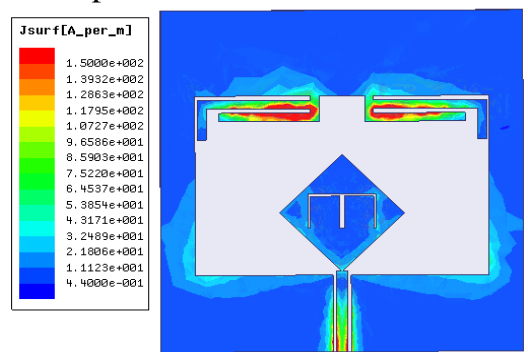

(a) $3.4 \mathrm{GHz}$
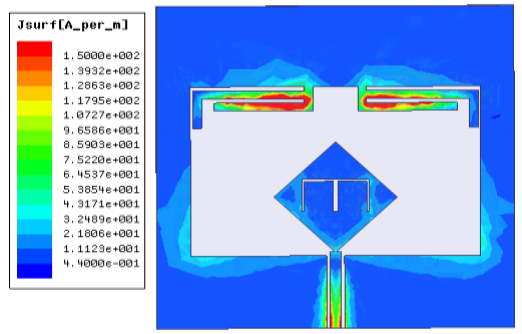

(b) $5.4 \mathrm{GHz}$

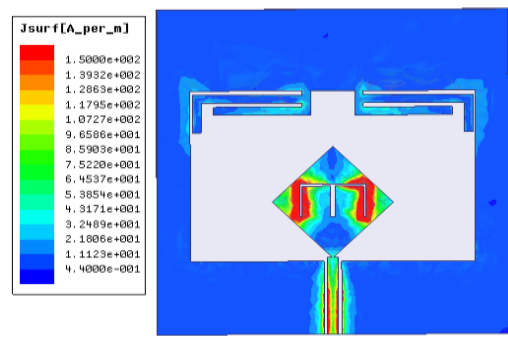

(c) $8.4 \mathrm{GHz}$

Fig. 5 The simulation results of the surface current.

Figure 6 shows the simulation result of the gain of the antenna in the UWB band. It can be concluded from the graphic analysis that the gain of the notch antenna in 3.1$3.6 \mathrm{GHz}, 5.2-5.8 \mathrm{GHz}$ and $8.2-8.7 \mathrm{GHz}$ are obvious reduced. In $3.4 \mathrm{GHz}$, the gain is $-4 \mathrm{~dB}$. In $5.4 \mathrm{GHz}$, the gain is $-9 \mathrm{~dB}$.In $8.4 \mathrm{GHz}$, the gain is $-8 \mathrm{~dB}$. On the other frequency , the gain of the antenna keeps in $2.5-5 \mathrm{~dB}$. It confirms that the antenna has good notch characteristics.

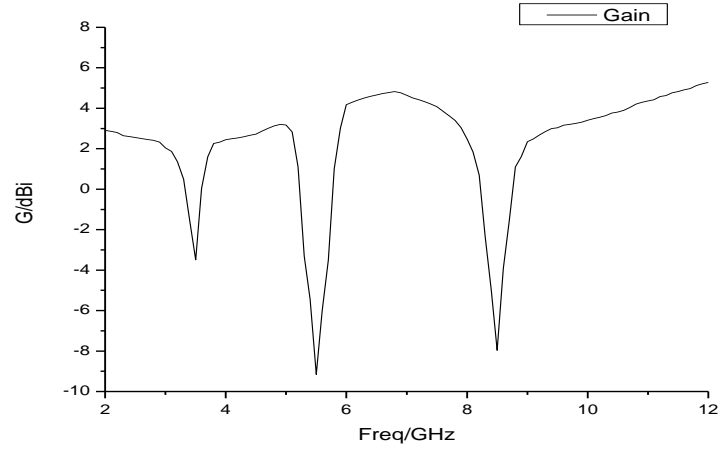

Fig. 6 The simulation result of the gain.

\section{Conclusion}

The ultra wideband antenna was proposed with three band notch characteristic in this paper. The whole size of this antenna is $32 \mathrm{~mm} \times 32 \mathrm{~mm} \times 0.508 \mathrm{~mm}$. In order to suppress the potential interference of the WiMAX system, WLAN system and ITU $8 \mathrm{G}$ system on the three communication system, in the rectangular wide slot add $\mathrm{L}$ shaped radiation unit and $\mathrm{E}$ groove. The notch characteristics in $3.1-3.6 \mathrm{GHz}, 5.2-5.8 \mathrm{GHz}$ and $8.2-8.7 \mathrm{GHz}$ were achieved by changing the length of Lshaped and $\mathrm{E}$ shape groove. The working frequency of the antenna is $3-12 \mathrm{GHz}$. It can cover the whole UWB band with omnidirectional radiation characteristics and stable gain. The antenna has the advantages of small size, simple structure, good performance and good practicability.

\section{Acknowledgements}

This work was supported by 2014 the Education Department of Guangdong Provincial special innovation projects No.2014KTSCX134.

\section{References}

[1] "Federal Communications Commission. First Report and Order Revision of Part 15 of the Commission Rules Regarding Ultra-Wideband Transmission Systems", (2002).

[2] C. S. Han, J. S. Tang. "UWB Slot Antenna with Dual Band-notched Characteristic", Video Engineering, Vol.39, No.5, pp.57-60, (2015).

[3] W. Hu, J. H. Zhang, L. Ma. "A band-notched UWB antenna with T-shaped slot", JOURNAL OF HEFEL UNIVERSITY OF TECHNOLOGY, Vol.34, No.7, pp. 1100-1103,(2011).

[4] S. T. Su. "Design of dual band-notched planar inverted cone ring antenna for UWB communications". Microwave \& Optical Technology Letters, Vol.56, No.2, pp. $284-287,(2014)$.

[5] H. L. Tang, J. L. Li, X. Zhang. "A ultra wideband antenna with dual band notch characteristic", ELECTRONICS WORLD, No.11, pp.177-178, (2016) 
[6] A. T. Wu, B. R. Guan. "Design and Research of a Compact CPW-fed UWB Antenna with Triple Band-notch Characteristic", Journal of microwaves, Vol.31, No.2, pp.15-19, (2015).

[7] A. Wu, B. Guan. "A Compact CPW-Fed UWB Antenna with Dual Band-Notched Characteristics", International Journal of Antennas \& Propagation, Vol.2013, No.3, pp.1-7, (2013).

[8] L. H. Ye, Q. X. Chu. "Improved Notch-Band Slot UWB Antenna with Small Size", ACTA ELECTRONICA SINICA, Vol.38, No.12, pp.2862-2866, (2010).

[9] J. Xu, D. Y. Shen, G. T. Wang, et al. "A Small UWB Antenna with Dual Band-Notched Characteristics", International Journal of Antennas \& Propagation, Vol.2012, No.2, pp.1018-1020,(2012).

[10] J. Liu, S. Gong, Y. Xu, et al. "Compact printed ultrawideband monopole antenna with dual band-notched characteristics", Electronics Letters, Vol.44, No.12, pp.710-711, (2008).

[11] S. T. Su. "Design of dual band-notched planar inverted cone ring antenna for UWB communications", Microwave \& Optical Technology Letters, Vol.56, No.2, pp.284 - 287,( 2014).

[12] L. Liu, S. W. Cheung, I. T. Yuk. "Deep band-notched ultra-wideband planar monopole antenna using meander lines", Microwave \& Optical Technology Letters, Vol.55, No.5, pp.1085 - 1091, (2013).

[13] N. Pouyanfar. "CPW-FED UWB antenna with bandstop properties", Microwave \& Optical Technology Letters, Vol.55, No.7, pp.1533 - 1537, (2013). 